\title{
Cloning and Expression of Randomly Mutated Bacillus subtilis $\alpha$-Amylase Genes in HB101
}

\author{
Mohammed Rabbani, ${ }^{1,2}$ Hamid MirMohammad Sadeghi, ${ }^{1}$ Fatemeh Moazen, ${ }^{1}$ \\ Mehran Rahimi, ${ }^{3}$ and Golnaz Salehi ${ }^{3}$ \\ ${ }^{1}$ Department of Pharmaceutical Biotechnology and Isfahan Pharmaceutical Sciences Research Centre, \\ School of Pharmacy and Pharmaceutical Sciences, Isfahan University of Medical Sciences, Isfahan 81746-73461, Iran \\ ${ }^{2}$ Department of Pharmacology, School of Pharmacy and Pharmaceutical Sciences, Isfahan University of Medical Sciences, \\ Isfahan 81746-73461, Iran \\ ${ }^{3}$ Isfahan Pharmaceutical Sciences Research Centre, School of Pharmacy and Pharmaceutical Sciences, \\ Isfahan University of Medical Sciences, Isfahan 81746-73461, Iran
}

Correspondence should be addressed to Mohammed Rabbani, rabanim@yahoo.com

Received 12 April 2011; Accepted 26 May 2011

Academic Editor: Triantafyllos Roukas

Copyright (C) 2011 Mohammed Rabbani et al. This is an open access article distributed under the Creative Commons Attribution License, which permits unrestricted use, distribution, and reproduction in any medium, provided the original work is properly cited.

\begin{abstract}
The aim of this study was to isolate and express the randomly mutated $\alpha$-amylase gene from $B$. subtilis strain 168. BS168F: $5^{\prime}$ gtgtcaagaatgtttgc- $3^{\prime}$ and BS168R: $3^{\prime}$-gttttgttaaaagatga- $5^{\prime}$ primers were used to amplify the amylase gene using the following cycle in error-prone PCR method: $94^{\circ} \mathrm{C}$ for $30 \mathrm{~s}, 40^{\circ} \mathrm{C}$ for $2 \mathrm{~min}$, and $72^{\circ} \mathrm{C}$ for $2 \mathrm{~min}$ in 30 cycles that were followed with $72^{\circ} \mathrm{C}$ for $2 \mathrm{~min}$ as a post cycle. E. coli XL1 blue was used as host for plasmid construction. Amylase enzyme activity assay was performed using continuous spectrophotometric procedures. Results of sequencing showed that sequence was cloned from the first ATG and with the correct open reading frame. Having confirmed the integrity of the insert, the gene was ligated into expression vector pET-15b and then further confirmed using digestion analysis. Amylase activity showed 3 clones with higher enzymatic activity compared with the wild type. Error-prone PCR method produced a mutated gene that provides amylase activity much higher than that of wild type. Sequencing the mutated genes should shed light on the important region of the genes that could be manipulated in future studies.
\end{abstract}

\section{Introduction}

$\alpha$-Amylases are extracellular enzymes which randomly cleave the $\alpha-1,4$ linkages between adjacent glucose units in the linear amylase chain, generating glucose, maltose, and maltotriose units [1]. According to the type of bonds they hydrolyze and their products, they are classified as $\alpha, \beta$, and $\gamma$ amylases [2]. They are among the most important commercial enzymes, with wide applications in starch processing, brewing, alcohol production, textile, paper, detergent, clinical, medicinal, and analytical chemistry [1]. Amylase enzymes make up approximately $25 \%$ of the enzyme market. Although $\alpha$-amylases can be derived from plants and animals, they are the enzymes from microbial sources (typically Bacillus spp.) that are generally used to meet the expanding industrial demands [3]. Mesophilic and thermophilic fungi are also good source of amylolytic enzymes due to their working conditions and reaction specificity properties [4].

The Gram-positive bacterium B. subtilis naturally thrives in the soil and the plant rhizosphere. Due to its life in unfavorable conditions, Bacillus produces and secretes a wide variety of enzymes with industrial applications [5]. $B$. subtilis is preferred organism, as it transports proteins across the cytoplasmic membrane into the growth medium [6]. Being an excellent model for investigating the mechanisms of gene regulation, differentiation, and metabolism, B. subtilis has been extensively studied in hundreds of laboratories worldwide for more than half a century using a variety of laboratory strains. The laboratory strain 168 is the only 
B. subtilis strain with known genomic sequence, obtained through an extensive collaboration more than ten years ago [7]. B. subtilis 168 was constructed by mutagenic X-rays and UV treatment of the wild-type B. subtilis (Marburg) strain [8].

Considering the widespread application of $\alpha$-amylases in different industrial processes, any improvement in the enzyme production, thermostability, and activity will have a direct impact on the process performance, economics, and feasibility. The requirements for an optimally performing enzyme are quite different for different industries, especially the optimal $\mathrm{pH}$ and temperature required. Protein engineering techniques have been applied to improve the different characteristics of a targeted enzymes by introducing mutations in the $\alpha$-amylases-encoding DNA sequence. The methods for protein engineering can be roughly categorized into two: site-directed mutagenesis and random mutagenesis. Site-directed mutagenesis is to introduce additions/deletions/substitutions of specific amino acids, and structural information of the targeted enzyme is essential to make those alternations. Random mutagenesis is to introduce mutations at random along the entire length of a gene using error-prone PCR [9]. Error-prone PCR method is widely used for constructing a randomly mutagenized DNA library [10]. This method has been successfully applied for various purposes such as substrate specificity, improve thermal stability, and to identify critical residues for protein-ligand interaction [10]. Considering the importance of amylase in various industries, the aim of the current project was to randomly mutagenise the bacillus subtilis $168 \alpha$-amylase gene using error-prone PCR technique. The mutated genes were later expressed in suitable expression vector and their enzymatic activities were compared with the wild-type enzyme.

\section{Materials and Methods}

2.1. Bacterial Strains, Plasmids, Enzymes, and Chemicals. Escherichia coli strains XL1Blue and B. subtilis 168 were purchased from PTCC (Iran) and DSMZ (Germany), respectively. All bacterial strains were cultured in Luria-Bertani (LB) liquid or on LB plates, supplied with appropriate antibiotics, at $37^{\circ} \mathrm{C}$. InsT/A clone PCR product cloning kit was purchased from Fermentas (Hungary). Restriction enzymes and reagents for gene manipulation were obtained from Fermentas and were used according to the manufacturer's recommendations. Primers were synthesized by Fazapazo (Iran). Genemorph II random mutagenesis kit was purchased from Stratagene (Switzerland). QIA quick gel extraction kit and high pure PCR template preparation kit were purchased from Roche (Germany). Electrophoresis equipment for agarose gel electrophoresis was from Bio-Rad. All other chemicals and reagents were of analytical grade and were purchased from Sigma or Merck unless otherwise stated. All buffers and solutions were prepared with Milli Q water (Millipore).

2.2. Media and Growth Conditions. E. coli and B. subtilis 168 were grown in Luria-Bertani (LB) medium, adjusted to
pH 7.2 with $\mathrm{NaOH}$ on a gyratory shaker with $220 \mathrm{rpm}$ at $37^{\circ} \mathrm{C}$. Ampicillin $50 \mu \mathrm{g} / \mathrm{mL}$ was used as the identical final concentrations, in plates and in liquid media.

2.3. Genomic DNA Extraction. Genomic DNA was isolated from B. subtilis cells according to Roche "high pure PCR template preparation kit" instruction manual. Briefly, cells were harvested in midexponential growth phase by centrifugation $(3000 \times \mathrm{g}, 5 \mathrm{~min})$ and suspended in PBS buffer (4.3 $\mathrm{mM} \mathrm{Na}_{2} \mathrm{HPO}_{4} \cdot 7 \mathrm{H}_{2} \mathrm{O}, 137 \mathrm{mM} \mathrm{NaCl}, 1.4 \mathrm{mM} \mathrm{KH}_{2} \mathrm{PO}_{4}$, and $2.7 \mathrm{mM} \mathrm{KCl}(\mathrm{pH} \mathrm{7.2)})$. Cells were treated with lysozyme $(10 \mathrm{mg} / \mathrm{mL}$ in $10 \mathrm{mM}$ Tris- $\mathrm{HCl}, \mathrm{pH} 8.0)$ for $30 \mathrm{~min}$ at $37^{\circ} \mathrm{C}$ and subsequently with proteinase $\mathrm{K}(100 \mathrm{mg} / \mathrm{mL})$ at $72^{\circ} \mathrm{C}$ for $10 \mathrm{~min}$. DNA was precipitated with 0.6 volumes of isopropanol and harvested by centrifugation $(10,000 \times \mathrm{g}$, $15 \min$ at $\left.4^{\circ} \mathrm{C}\right)$.

2.4. Random Mutagenesis of $\alpha$-Amylase Gene. The $\alpha$-amylase gene of BS168 was amplified by Genemorph II random mutagenesis kit using purified genomic DNA as a tem plate. Based on the deduced ORF of the amylase gene, oligonucleotide primers were synthesized to amplify the intact region of $\alpha$-amylase. The forward primer, $B S 168 \mathrm{~F}$ 5'-CTAATTCCATGGGGATGTTTGCAAAACGATTCA-3', introduced $\mathrm{NcoI}$ site (underlined) just prior to the initiation site of amylase (italics). The reverse primer, BS168R $5^{\prime}$-GAA CGCGGATCCTCAATGGGGAAGAGAA-3', was complementary to the nucleotides positioned before the termination codon and introduced BamHI site (underlined) just downstream of the termination codon (italics). These primers correspond to the boundaries of the coding sequence of the gene from translation initiation to the termination codon (underlined), thus the final PCR product was $1983 \mathrm{~Kb}$.

The PCR mixture consisted of $5 \mu \mathrm{L}$ of $10 \mathrm{X}$ Mutazyme II reaction buffer, $1 \mu \mathrm{L}$ of $40 \mathrm{mM}$ mutagenic dNTP mix ( $200 \mu \mathrm{M}$ each final), $25 \mu \mathrm{L}$ each of forward and reverse primers $(2.5 \mu \mathrm{M}$ each primer $), 1 \mu \mathrm{L}$ of Mutazyme II DNA polymerase $(2.5 \mathrm{U} / \mu \mathrm{L})$, and $400 \mathrm{ng}$ of template in a total volume of $50 \mu \mathrm{L}$.

The PCR was performed with the following cycling profile: initial denaturation at $94^{\circ} \mathrm{C}$ for $5 \mathrm{~min}$, followed by 35 cycles of $1 \mathrm{~min}$ denaturation at $94^{\circ} \mathrm{C}$, annealing at $55^{\circ} \mathrm{C}$ for $2 \mathrm{~min}$, and extension at $72^{\circ} \mathrm{C}$ for $3 \mathrm{~min}$. The time for the final extension step was increased to $20 \mathrm{~min}$.

The PCR product was recovered using the QIA quick gel extraction kit, and the amplified product was then purified and cloned into pTZ57R vector. Ligation stage was achieved by adding T4 DNA ligase to solution containing PCR product and $\mathrm{pTZ} 57 \mathrm{R}$ vector at $22^{\circ} \mathrm{C}$ overnight. The recombinant plasmids were transformed into $E$. coli XL1Blue and HB101, using the Hanahan protocol [11], for amplification. Plasmid DNA from the resulting clones was purified using the QIAprep spin miniprep kit and screened through restriction digestion for the insert of the PCR product. Plasmids identified as carrying the insert were digested with $\mathrm{NcoI} / \mathrm{BamHI}$, and after isolation through gel electrophoresis and purification, the insert was ligated into the expression vector pET-15b predigested with $\mathrm{NcoI}$ and BamHI. The 
ligation mixture was transformed into E. coli HB101 for plasmid propagation. Recombinant plasmids were screened through $\mathrm{NcoI} /$ BamHI digestion, and clones containing the insertion of the intact coding region for $\alpha$-amylase were identified. The presence of $\alpha$-amylase gene was determined at $92^{\circ} \mathrm{C}$ using the $12 / \mathrm{KI}$ method as described previously [12].

2.5. Enzyme Assay. Amylase activity was measured by the dinitrosalicylic acid (DNS) method (Rick, 1974). Soluble starch was prepared by heating a suspension of starch at concentrations ranging from 0 to $2 \mathrm{mg} / \mathrm{mL}$ in $100 \mathrm{mM}$ phosphate buffer $\left(77 \mathrm{mM} \mathrm{Na}_{2} \mathrm{HPO}_{4}, 23 \mathrm{mM} \mathrm{NaH}_{2} \mathrm{PO}_{4}\right)$ until a homogeneous, viscous solution was obtained. The reaction mixture containing $1 \%$ soluble starch and $1 \mathrm{~mL}$ of enzyme solution was kept for $12 \mathrm{~min}$ at $25^{\circ} \mathrm{C}$. To the above reaction, $0.1 \mathrm{~mL}$ of DNS reagent was added, and the mixture was boiled for $15 \mathrm{~min}$. After cooling, the reaction mixture was diluted by distilled water, and the absorbance was measured at $540 \mathrm{~nm}$. One unit of amylase activity was defined as the amount of enzyme causing the release of $1 \mu$ mole of reducing sugars in one min under the assay conditions.

2.6. Statistics. The statistical analysis of the results was carried out using SigmaStat 3.10 program and based on analysis of variance (ANOVA) followed by the Tukey posthoc test. $P<0.05$ was considered significant. All data are expressed as mean \pm S.E.M.

\section{Results}

3.1. Construction of the Expression Vector pet-15b. PCR amplification of the $\alpha$-amylase gene of BS168 under normal or random mutagenesis conditions resulted in production of a band in the expected region of $1983 \mathrm{bp}$ as is shown in Figures 1(a) and 1(b), respectively. BS168F and BS168R primers correspond to the boundaries of the coding sequence of the $\alpha$-amylase gene from translation initiation to the termination codon, thus the final PCR product of $1983 \mathrm{bp}$ should be observed.

Using Qia quick gel extraction kit, PCR products were purified and used for ligation into the pTZ57R plasmid with the aid of T/A cloning kit. The constructs were then used to transform E. coli XL1-Blue and E. coli HB101. From the library of pTZ57R bacterial plasmids, several clones were shown to contain the $\alpha$-amylase gene in the correct orientation. The cloned DNA fragment in pTZ57R was digested from upstream and downstream of the gene by BamHI and NcoI restriction enzymes, and the 1983 bp DNA fragment was inserted into the same endonuclease sites of the pET-15b expression vector. The orientation of the insert in the vector was confirmed using EcoRI restriction enzyme as depicted in Figure 2. Digestion of the recombinant pET-15b with EcoRI should produce two bands in the region of 1764 and $5857 \mathrm{bp}$.

The amylase activity of the recombinant vector was assessed by transforming the vector in E. coli HB101. The cells harbouring the plasmid were grown on ampicillin plate parallel with negative controls cells containing pET-15b. All

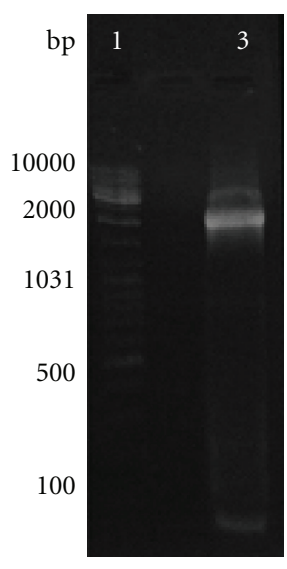

(a)

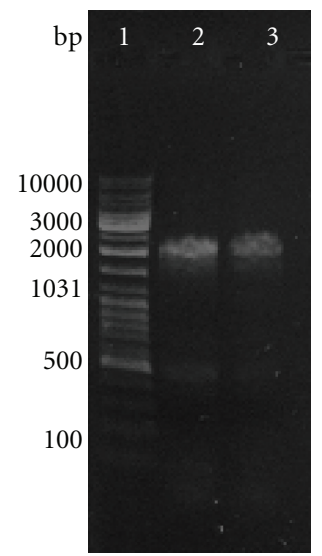

(b)
FIGURE 1: PCR amplification of $\alpha$-amylase gene of BS168. (a) amplification of $\alpha$-amylase gene. Lanes 1: DNA molecular size marker, 3: PCR product. (b) Error-prone PCR product of $\alpha$-amylase gene. Lanes 1: DNA molecular size marker, 2 and 3: error-prone PCR products. $10 \mu \mathrm{L}$ of samples were applied to a $0.7 \%$ agarose gel for electrophoretic separation.

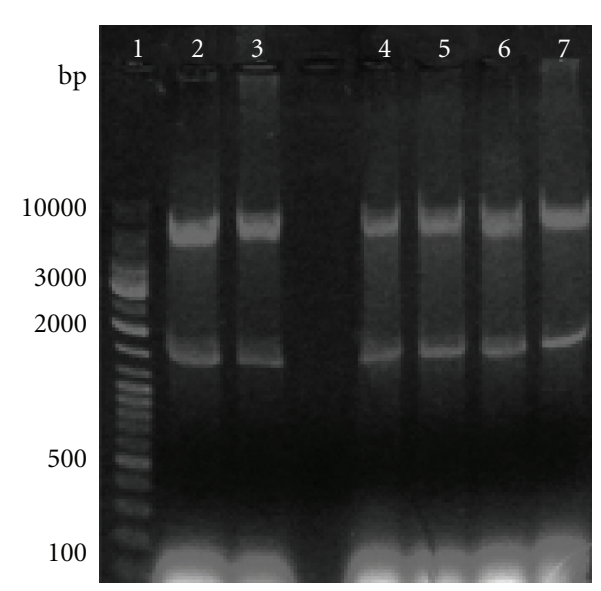

FIGURE 2: Digestion of the pET-15b containing $\alpha$-amylase plasmid with EcoRI restriction enzyme. Lane 1: molecular weight marker. Lanes: 2, 3, 5, 6, and 7: digested pET-15b plasmid harbouring $\alpha$-amylase with EcoRI restriction enzyme.

the colonies of E. coli carrying PET plasmid tested by the KI-I2 method showed haloes in starch-containing plates indicating the presence of $\alpha$-amylase gene.

3.2. Nucleotide Sequences of B. subtilis $168 \alpha$-Amylase Gene. The complete nucleotide sequence of the DNA fragment encompassing the $\alpha$-amylase gene was determined with both strands using T7 primers. Sequence analysis with BLAST program revealed $100 \%$ homology between this gene and standard $\alpha$-amylase gene that outlined in GenBank with NC_000964 accession number.

3.3. Enzymatic Properties of Randomly Mutated Amylase Genes. A comparison of the catalytic activity of the clones 
TABLE 1: The $\alpha$-amylase activity of wild, error-prone gene and empty vector.

\begin{tabular}{lcc}
\hline Samples & $\begin{array}{c}\text { Mean absorbance } \\
\text { at 540 } \mathrm{nm}\end{array}$ & $\begin{array}{c}\alpha \text {-amylase activity } \\
(\mathrm{U} / \mathrm{mL})\end{array}$ \\
\hline Sample 3 & 0.306 & $605.39 \pm 0.0416$ \\
Sample 27 & 0.278 & $553.92 \pm 0.0134$ \\
Sample 6 & 0.377 & $735.29 \pm 0.0124$ \\
Wild-type 1 & 0.283 & $561.27 \pm 0.0015$ \\
Wild-type 2 & 0.271 & $541.67 \pm 0.0032$ \\
B. subtilis & 0.0217 & $95.10 \pm 0.0107$ \\
Plasmid pET15-b & 0.0233 & $97.79 \pm 0.0153$ \\
\hline
\end{tabular}

produced by error-prone PCR with those of the wild-type enzyme was carried out using soluble starch as a substrate, measuring the release of reducing sugars. Amylase activity was first measured under different IPTG concentrations $(0.25,0.5,1,1.5 \mathrm{mM})$ in both supernatant and intracellular fractions of cells during different times $(4,17,24$, and 48). E. coli HB101 cells harbouring pET-15b were used as a negative control and represented no amylase activity. IPTG concentration required for optimal amylase starch hydrolysis activity was $0.5 \mathrm{mM}$. The time for optimum expression cultivation condition for amylase activity was found to be $4 \mathrm{~h}$. From the total of 97 clones that were screened, 3 samples showed the maximum enzymatic activities (Table 1). The activities of the three samples were significantly higher than that of the wild types $(P<0.05)$.

\section{Discussion}

The aim of the current project was to isolate amylase genes from B. subtilis 168 and then using error-prone PCR technique to mutate the PCR product. Bacillus species are among bacteria that are widely used for production of commercial enzymes. At present, about $60 \%$ of the commercially available enzymes are produced by Bacillus species, mostly being homologous proteins that are naturally secreted in the growth medium such as alkaline proteases as washing agent or amylases for the starch industry $[13,14]$. The first step in the process of obtaining recombinant protein was to select a suitable microorganism that carries the gene of the request protein or enzyme. In this study, B. subtilis 168 was used as a source of DNA for amylase gene. B. subtilis 168, which is second only to E. coli in the extent to which tools of genetic and protein engineering have been developed, has contributed to the extensive use for the industrial production of bioengineered materials. The advantage of B. subtilis 168 over other bacterial strains has been increased even more by the availability of the complete sequence of the B. subtilis 168 genome [15].

Using the designed pair of primers, the PCR reaction was carried out under a standard condition that was stated in Section 2 . The expected band of approximately $2000 \mathrm{bp}$ was observed after several repeats and changes in annealing temperature. Transformation of recombinant pTZ57R plasmid in two E. coli strains, XL1-Blue, and HB101 produced several colonies which harboured the recombinant plasmid. EcoRI digestion of the recombinant plasmid resulted in production of several bands on agarose gel. EcoRI cuts amylase gene at $538 \mathrm{bp}$ region and the pTZ57R cloning vector at $615 \mathrm{bp}$ region. Depending on the orientations of $\alpha$-amylase gene in pTZ57R plasmid, two different size bands would be expected. If the orientation of $\alpha$-amylase gene is such that its $5^{\prime}$ end is near T7 promoter, then, following the digestion with EcoRI enzyme, two bands of 537 and 4296 bp should be produced, otherwise, two bands at about 1480 and $3389 \mathrm{bp}$ regions are resulted. Double digestion of the recombinant plasmid with $\mathrm{NcoI}$ and $\mathrm{BamHI}$ restriction enzymes provided the final endorsement for the correct orientation of the insert. As explained previously, when the double digestion was carried out only two bands of approximately, $2000 \mathrm{bp}$ and $2900 \mathrm{bp}$ are observed which corresponded to the insert and the pTZ57R, respectively.

Having confirmed the integrity of the insert in the plasmid, the next step was to determine the sequence of the insert. T7 primers were used for nucleotide sequencing of DNA fragment encompassing the $\alpha$-amylase gene. The sequence of the fragment was analyzed using BLAST program and showed a $100 \%$ homology with the standard $\alpha$ amylase gene that outlined in GenBank with NC_000964 accession number.

A large number of colonies containing the recombinant plasmids were selected and analyzed for the existence of the newly inserted wild-type or error-prone amylase genes in them. After confirmation of the clones at this stage, amylase activity was measured according to the method that was stated in previous sections. From the total of 97 clones that were analyzed, 3 clones proved to have an enzymatic activity greater than those of the wild-type genes. The activity of recombinant amylases is relatively poor compared to those of most bacterial $\alpha$-amylases. Comparison of this activity to closely related amylases is difficult as most have been partially or completely purified. These 3 clones are now required to be taken for further detailed studies. The fact that only 3 clones had activity greater than those of wild type requires further adjustment in the process. Alteration in the process of mutation by using another error-prone kit or manually altering the gene could be an alternative pursuit that due to lack of fund could not be seriously carried out in this study. Confirmation of the amylase activity by other methods and the sequencing of the gene could pave the way for production in the lab scale. Testing of the enzyme for activity in industrial process is another point that is worth perusing in future studies.

\section{References}

[1] S. Kar, R. C. Ray, and U. B. Mohapatra, "Alpha-amylase production by Streptomyces erumpens MTCC 7317 in solid state fermentation using response surface methodology (RSM)," Polish Journal of Microbiology, vol. 57, no. 4, pp. 289-296, 2008.

[2] O. Kirk, T. V. Borchert, and C. C. Fuglsang, "Industrial enzyme applications," Current Opinion in Biotechnology, vol. 13, no. 4, pp. 345-351, 2002.

[3] K. Kurosawa, T. Hosaka, N. Tamehiro, T. Inaoka, and K. Ochi, "Improvement of Alpha-amylase production by modulation 
of ribosomal component protein S12 in Bacillus subtilis 168," Applied and Environmental Microbiology, vol. 72, no. 1, pp. 7177, 2006.

[4] V. Champreda, P. Kanokratana, R. Sriprang, S. Tanapongpipat, and L. Eurwilaichitr, "Purification, biochemical characterization, and gene cloning of a new extracellular thermotolerant and glucose tolerant maltooligosaccharide-forming alphaamylase from an endophytic ascomycete Fusicoccum sp. BCC4124," Bioscience, Biotechnology and Biochemistry, vol. 71, no. 8, pp. 2010-2020, 2007.

[5] T. R. Kouwen and J. M. van Dijl, "Applications of thioldisulfide oxidoreductases for optimized in vivo production of functionally active proteins in Bacillus," Applied Microbiology and Biotechnology, vol. 85, no. 1, pp. 45-52, 2009.

[6] T. R. Kouwen, J. Y. Dubois, R. Freudl, W. J. Quax, and J. M. van Dijl, "Modulation of thiol-disulfide oxidoreductases for increased production of disulfide-bond-containing proteins in Bacillus subtilis," Applied and Environmental Microbiology, vol. 74, no. 24, pp. 7536-7545, 2008.

[7] C. R. Harwood and A. Wipat, "Sequencing and functional analysis of the genome of Bacillus subtilis strain 168," FEBS Letters, vol. 389, no. 1, pp. 84-87, 1996.

[8] A. Srivatsan, Y. Han, J. Peng et al., "High-precision, wholegenome sequencing of laboratory strains facilitates genetic studies," PLoS Genetics, vol. 4, no. 8, Article ID e1000139, 2008.

[9] O. Kuchner and F. H. Arnold, "Directed evolution of enzyme catalysts," Trends in Biotechnology, vol. 15, no. 12, pp. 523-530, 1997.

[10] T. Koyanagi, E. Yoshida, H. Minami, T. Katayama, and H. Kumagai, "A rapid, simple, and effective method of constructing a randomly mutagenized plasmid library free from ligation," Bioscience, Biotechnology and Biochemistry, vol. 72, no. 4, pp. 1134-1137, 2008.

[11] D. Hanahan, "Techniques for transformation of E. coli," in DNA Cloning. A Practical Approach, D. Glover, Ed., pp. 109135, IRL Press, Oxford, UK, 1985.

[12] K. A. Laderman, K. Asada, T. Uemori et al., "Alpha-amylase from the hyperthermophilic archaebacterium Pyrococcus furiosus. Cloning and sequencing of the gene and expression in Escherichia coli," Journal of Biological Chemistry, vol. 268, no. 32, pp. 24402-24407, 1993.

[13] I. Palva, "Molecular cloning of alpha-amylase gene from Bacillus amyloliquefaciens and its expression in B. subtilis," Gene, vol. 19, no. 1, pp. 81-87, 1982.

[14] M. Simonen and I. Palva, "Protein secretion in Bacillus species," Microbiological Reviews, vol. 57, no. 1, pp. 109-137, 1993.

[15] F. Kunst, N. Ogasawara, I. Moszer et al., "The complete genome sequence of the gram-positive bacterium Bacillus subtilis," Nature, vol. 390, no. 6657, pp. 249-256, 1997. 

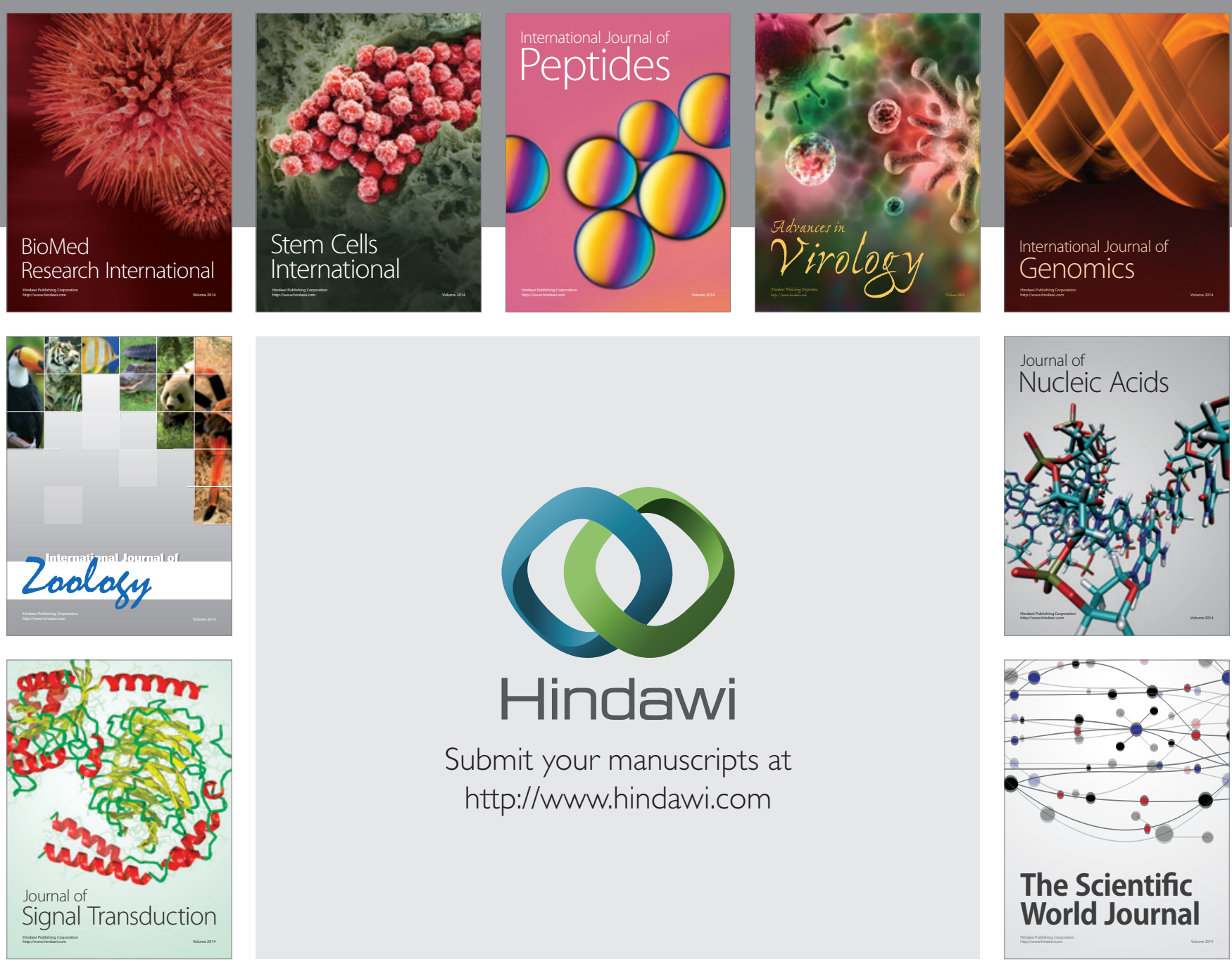

Submit your manuscripts at

http://www.hindawi.com
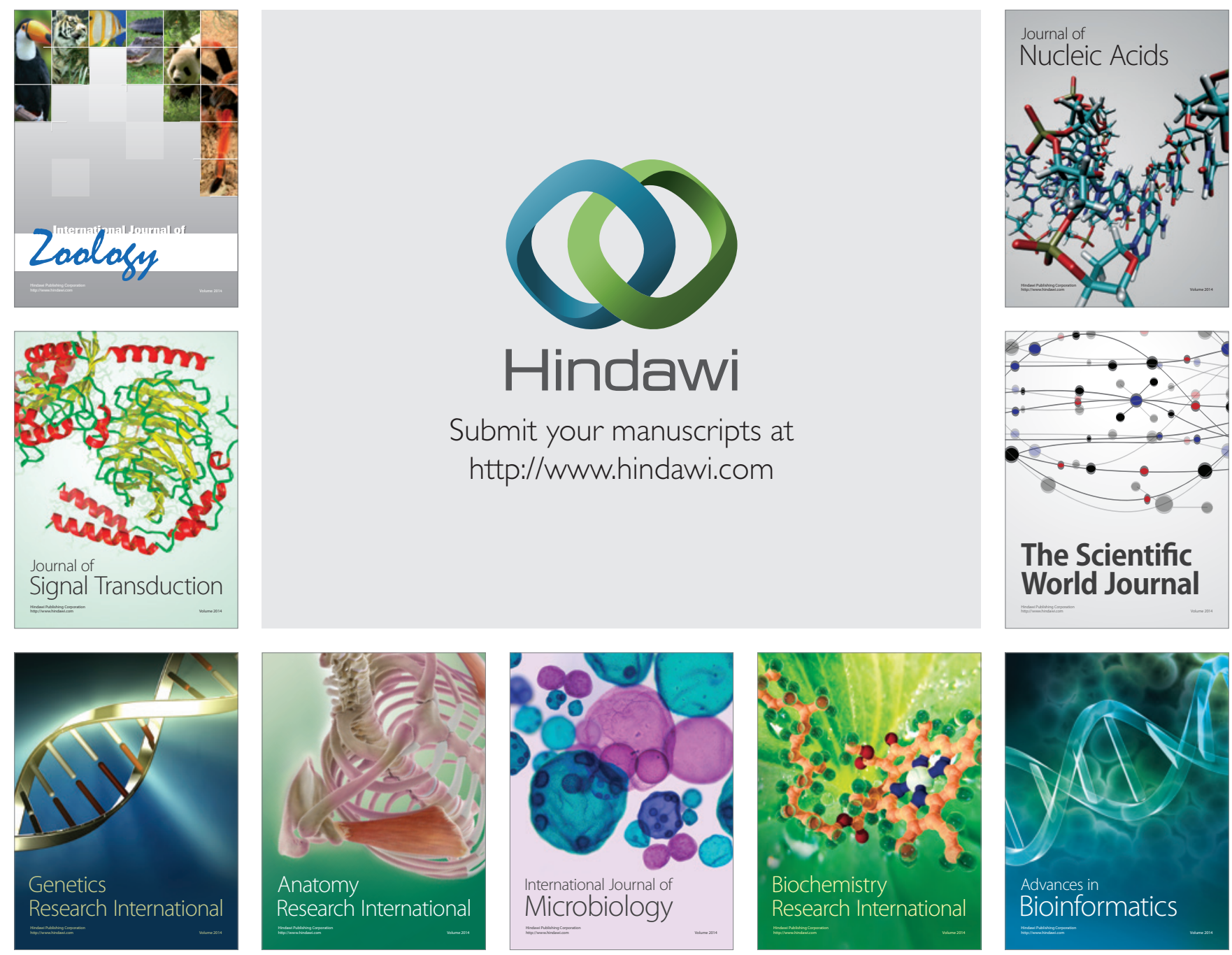

The Scientific World Journal
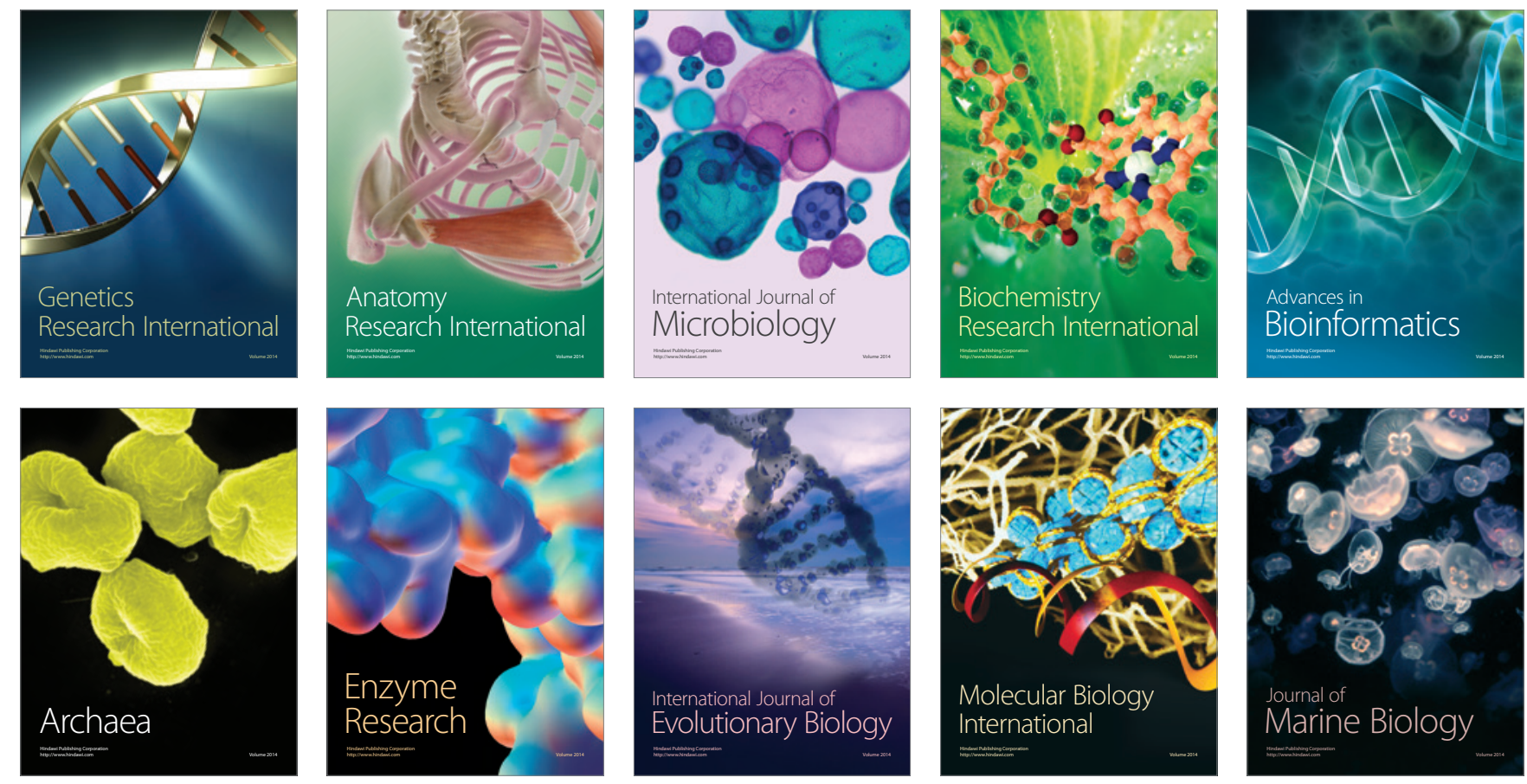